\title{
Study on the Influence Mechanism of Cross-border E-commerce and Foreign Trade Import and Export
}

\author{
Yuan Wang, Jing Wu*, Yihua Zhang \\ School of Business Administration, JiMei University, Jimen, Xiamen, China
}

Keywords: Cross-border e-commerce; Import and export trade; VAR model

\begin{abstract}
This paper selects the total amount of foreign trade import and export transactions and the total amount of cross-border e-commerce transactions time series data of the National Bureau of Statistics for 2004-2018, constructs a vector auto-regressive model (VAR), and uses co-integration test, Granger causality test, impulse response function and variance decomposition to quantitatively analyze the influence mechanism relationship between the total amount of foreign import and export trade and cross-border e-commerce in China. The research results show that there is a long-term stable relationship between the total import and export trade of our country and the cross-border e-commerce, and the Granger one-way causality between the cross-border e-commerce and the foreign import and export trade of our country. According to the results of the impulse response function, the effect will gradually become smaller over time.
\end{abstract}

\section{Introduction}

According to the latest report issued by the Institute of Electronic Commerce of the Ministry of Commerce Research Institute in June 2019, China's cross-border e-commerce development report 2019, China's cross-border e-commerce has maintained a steady rise in recent years, the total volume of transactions has increased year by year, and the industrial structure of the whole cross-border e-commerce has been continuously optimized. As one of the important cross-border e-commerce markets in the world, the scope of cross-border e-commerce trade in our country is gradually expanding, not only in export, but also in the source countries. And with the continuous improvement of the construction of "Belt and Road ", China's trade with the Silk Road along the country is more frequent, and the transaction of Silk Road e-commerce has become an important part of cross-border e-commerce in China, but also a bright spot in China's foreign trade exchanges. China's cross-border e-commerce transactions have been increasing year by year in recent years, according to monitoring data from the E-commerce Research Center, with a cross-border e-commerce transaction volume of about 5.4 trillion yuan in 2015 and 6.7 trillion yuan in 2016 [1], the turnover of cross-border e-commerce transactions in 2017 is about 8 trillion yuan, and the turnover of cross-border e-commerce transactions in 2018 is about 9 trillion yuan. It can be predicted that in the next few years, China's cross-border e-commerce will continue to maintain a steady and rapid development.

The rapid development of cross-border e-commerce in recent years, as a new mode of trade and new forms of business, whether from the market space or development prospects, the future development space is very large, the specific performance is mainly in the following aspects: first, the rapid growth of user-scale trading volume. Second, people's consumption demand and the upgrading of their consumption concept, the current consumption upgrade demand is very exuberant, "post-80s", "post-90s" or even "post-00s" people become the main participation group in cross-border e-commerce, the group's concern in the purchase of goods has changed, than their parents and elders, will become more inclined to food safety whether there is quality assurance, whether the variety of goods can be selected enough and whether the price is reasonable and so on. Third, overseas commodity cognition promotion. Therefore, it is not difficult to see that it is of great significance to study the change of cross-border e-commerce in recent years. 


\section{Summary of the Literature}

Wenlong Zhu and other scholars have established a three-stage model to study consumers' willingness to purchase in cross-border e-commerce transactions. Product description and product awareness have a positive effect on trust and belief, while platform sustained participation and platform situational participation have a positive impact on trust [2]. Zhong Lingling (2018) establishes regression model to analyze the impact of cross-border e-commerce on China's import and export trade [3]. Dai Zongqun (2018) used the data of cross-border e-commerce and related import and export trade in Shanghai Free Trade Area to analyze the relationship between cross-border e-commerce and import and export trade [4]. Zan Jinmiao (2018) studied the impact of cross-border e-commerce on import and export trade in Guangzhou, and provided some suggestions for promoting the development of cross-border e-commerce and import and export trade in China [5]. Xiao Ying (2018) adopts VAR model, Granger test method and unit root test to quantitatively analyze the relationship between cross-border e-commerce and traditional foreign trade and the influence of cross-border e-commerce on traditional foreign trade [6].Wang Xirong (2018) believes that the financial crisis in 2008 has brought disaster to the world economy, but also brought new opportunities for the development of cross-border e-commerce. Before that, the total amount of cross-border e-commerce transactions in China was in a depressed state, but in the following eight years, the scale increased more than eight times than before, and cross-border e-commerce has gradually developed into an important driving force for the growth of China's total foreign trade [7]. In general, Chinese scholars have also carried out relevant analysis and research on the import and export of cross-border e-commerce and traditional foreign trade, and put forward constructive suggestions and suggestions.

\section{Proven Research}

\subsection{Data sources and data processing}

The data are from the data released by the National Bureau of Statistics in 2004-2018, because the original time series are usually unstable, and the unstable time series cannot establish a stable vector auto-regressive model, so in order to be able to be the time series to become stationary, the data of each variable is first tested by natural logarithm. After the test, it is found that it is still not stationary, and the first-order difference processing is continued. The above processing of the original time series will not affect the co-integration relationship between the original variables, but also eliminate the possible heteroscedasticity between the variables to some extent. The total amount of raw data foreign trade import and export transactions is named MT, and the total amount of cross-border e-commerce transactions is named EC. After the logarithmic processing, the total foreign trade import and export transactions sequence is named LMT, and the total cross-border e-commerce transaction sequence is named LEC. After the first order difference processing, the total foreign trade import and export transaction sequence is named DLMT, the cross-border e-commerce transaction total sequence is named DLEC, the software used to build the vector auto-regressive model and carry out the related inspection process is Eviews9.0. Due to space limitations, the original data, the data after the logarithmic processing is performed on the original data, and the data after the first-order difference processing are omitted here.

\subsection{Unit root test}

A stationary sequence or a non-stationary sequence with the same order is a time series requirement for Granger causality test. The unit root test is to test the stability of the time series, because only a stationary time series can be measured and analyzed, otherwise it will easily lead to pseudo-regressive [8]. In this paper, the unit root test is carried out after logarithm of each variable and first order difference treatment. The test results are shown in Table 1.

$\mathrm{C}$ in Table 1 represents the constant term at the time of the ADF test, $\mathrm{T}$ represents the time trend term at the time of the ADF test, and K represents the number of lag periods at the time of the ADF test. According to the test results in Table 1, the PROB value of each variable is greater than 0.05 
after taking the logarithm, so the time series formed by the original time series after taking the logarithm is also unstable, but the time series of the first order difference after taking the logarithm is the stationary time series. Since the original sequence of variables is non-stationary and pseudo-regressive may exist, we need to pass the co-integration test to test whether there is a stable relationship between variables [9].

Table 1 ADF unit root test results

\begin{tabular}{|c|c|c|c|c|c|}
\hline Variables & $(\mathrm{C}, \mathrm{T}, \mathrm{K})$ & ADF value & $5 \%$ threshold & PROB & Conclusions \\
\hline LMT & $(\mathrm{C}, 0,0)$ & -2.512683 & -3.098896 & 0.1333 & Unsmooth \\
\hline DLMT & $(0,0,0)$ & -2.357224 & -1.970978 & 0.0229 & Smooth \\
\hline LEC & $(\mathrm{C}, \mathrm{T}, 3)$ & -2.930536 & -3.933364 & 0.1921 & Unsmooth \\
\hline DLEC & $(\mathrm{C}, 0,0)$ & -6.460047 & -3.144920 & 0.0003 & Smooth \\
\hline
\end{tabular}

\subsection{Determination of optimal lag order}

Because different lag order will lead to different significance of vector auto-regressive model, the optimal lag order should be determined before establishing vector auto-regressive model. In this paper, SC information criterion, likelihood ratio test statistics (LR), HQ information criterion, AIC information criterion and final prediction error (FPE) are used to determine the optimal lag order [10]. The inspection results are shown in Table 2.

Table 2 Values of LR, FPE, AIC, SC and HQ in phase 2

\begin{tabular}{|c|c|c|c|c|c|c|}
\hline Lag (lag order) & LogL & LR & FPE & AIC & SC & HQ \\
\hline 0 & 19.14083 & NA* $^{*}$ & $0.000197 *$ & $-2.856805^{*}$ & $-2.775988^{*}$ & $-2.886727 *$ \\
\hline 1 & 19.60351 & 0.694017 & 0.000363 & -2.267252 & -2.024798 & -2.357017 \\
\hline 2 & 23.01347 & 3.978284 & 0.000436 & -2.168911 & -1.764822 & -2.31852 \\
\hline
\end{tabular}

Since the software will automatically mark "*" after the best value, it is not difficult to see from the test results in Table 2 that the values of LR, FPE, AIC, SC and HQ are all optimal when the lag order is 0 , that is, the best lag order recommended by the above five methods is 0 .

\subsection{Johansen co-integration Inspection}

This paper selects johansen co-integration test as the research method to conduct co-integration test on the time series of the total amount of foreign trade import and export transactions and the total amount of cross-border e-commerce transactions, and performs co-integration test on the variables (LMT and LEC) after natural logarithm of the original time series. The test results are shown in table 3.

Table 3 Chart of measuring results

\begin{tabular}{|c|c|c|c|c|}
\hline $\begin{array}{c}\text { The number of co-integration relations } \\
\text { under the original hypothesis }\end{array}$ & Eigenvalue & Trace test statistics & $5 \%$ threshold & $\begin{array}{c}\text { Probability of } \\
\text { test statistics }\end{array}$ \\
\hline There are zero co-integration relationships & 0.653701 & 15.23308 & 15.49471 & 0.0447 \\
\hline $\begin{array}{c}\text { There is at most one co-integration } \\
\text { relationship }\end{array}$ & 0.105349 & 1.447186 & 3.841466 & 0.2290 \\
\hline
\end{tabular}

As can be seen from table 3, the trace statistics of Johansen indicate that: at the level of significance of $5 \%$ is to reject the original assumption that there is no co-integration relationship and accept the original assumption that there is at most one co-integration relationship. Therefore, there is a co-integration relationship between the two variables at a significant level of $5 \%$, indicating a long-term stable relationship between them [11].

The following co-integration equations can be obtained as shown:

$$
\mathrm{LMT}=0.257788 \mathrm{LEC}
$$

It can be seen from the estimated co-integration equation (1) that there is a long-term stable equilibrium relationship between the total amount of foreign trade import and export transactions and the total amount of cross-border e-commerce transactions in China. 


\subsection{Granger causality test}

Take the natural logarithm of the original time series and then carry out the stable sequence of the first order difference, establish the variable model of the total amount of foreign trade import and export transactions and the total amount of cross-border e-commerce transactions, and carry out the Granger causality test on the original hypothesis, and the test results are shown in table4.

Table 4 Principal component table

\begin{tabular}{|l|l|l|l|}
\hline Null hypothesis & Obs & F-statistic & Prob \\
\hline DEC dose not Granger cause DMT & 11 & 0.48748 & 0.6365 \\
\hline DMT dose not Granger cause DEC & & 7.27913 & 0.0249 \\
\hline
\end{tabular}

From table 4, it can be seen that at the significant level of 5\%, the change of the total amount of foreign import and export in China is the Granger reason for the development of cross-border e-commerce. This is because in the general environment, the overall growth as a base, the number of large, so can drive the development of cross-border e-commerce. According to the actual situation, in recent years, the country has vigorously promoted the economic development along the "Belt and Road ", not only deepening the degree of foreign trade exchanges in China, but also driving the cross-border e-commerce transactions between China and the countries along the" Belt and Road ".

\subsection{Vector auto-regressive model (VAR) stability analysis}

Only with a stationary VAR model, the impulse response is convergent, and the analysis is of economic significance. Therefore, the established VAR model should be tested for stability [12] .the unit root of the model has 4 , as shown in figure 1 , all points exist within the unit circle, indicating that the constructed vector auto-regressive model is stable.

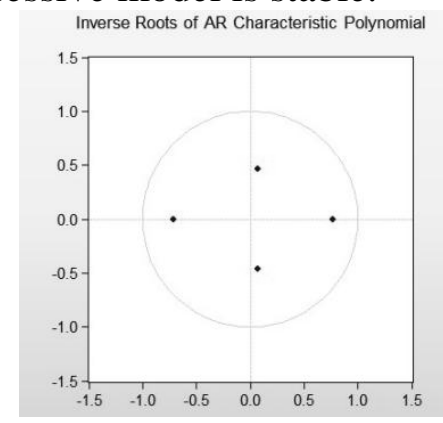

$\mathrm{X}$-axis: real part

Y-axis: The coefficient of imaginary part i

Fig.1 Results of unit circle and characteristic root test

\subsection{Pulse response function}

Based on the established vector auto-regressive model, we will depict the impulse response function of the total amount of foreign trade import and export transactions in China and the total amount of cross-border e-commerce transactions in China, and the results are shown in Fig.2.

The transverse coordinates in figure 2 indicate the number of periods, the longitudinal axis indicates the magnitude of the impulse response function, the solid line indicates the trend after the impact of the total growth of import and export transactions in china, and the dotted lines on both sides of the trend are twice the standard error of the trend . From the top dotted line, it can be seen that after the impact reaches its maximum in the first two periods, the impact gradually becomes stable. From the trajectory of the impulse response value in Fig.2, it can be seen that the initial several periods of shock are large and the influence is relatively large, and then gradually tend to 
smooth the situation.

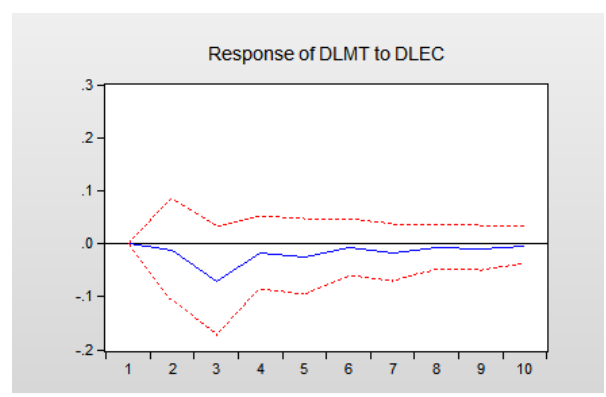

X-axis: the number of periods

Y-axis: the magnitude of the impulse response function

Figure 2 Response of China's external imports and exports to cross-border e-commerce disturbances

\subsection{Variance decomposition}

The impulse response function is used to analyze the response of the total amount of cross-border e-commerce transactions in China to the impact of the total amount of import and export transactions in China.The total amount of cross-border e-commerce transactions in China will be analyzed by using the variance decomposition method. The results are shown in Figure 3.

\begin{tabular}{cccc}
\hline \hline Period & S.E. & DLMT & DLEC \\
\hline \hline 1 & 0.144636 & 100.0000 & 0.000000 \\
2 & 0.145142 & 99.30438 & 0.695622 \\
3 & 0.165759 & 80.93764 & 19.06236 \\
4 & 0.167522 & 80.22222 & 19.77778 \\
5 & 0.169484 & 78.40614 & 21.59386 \\
6 & 0.169666 & 78.25845 & 21.74155 \\
7 & 0.170569 & 77.46163 & 22.53837 \\
8 & 0.170721 & 77.36741 & 22.63259 \\
9 & 0.170984 & 77.13368 & 22.86632 \\
10 & 0.171029 & 77.10066 & 22.89934 \\
\hline \hline Cholesky Ordering: DLMT DLEC & \\
\hline \hline
\end{tabular}

Figure 3 Variable DLMT (Total Foreign Import and Export Transactions) Variance Decomposition Results

In Figure 3, the Period column is the number of periods for variance decomposition, i.e., the forecast period for the total standard deviation of external import and export transactions; S.E. Listed is the standard deviation for the forecast of total foreign import and export transactions; DLMT is the percentage of the total forecast variance of foreign import and export transactions arising from the total volume of foreign import and export transactions itself; DLEC is the percentage of the total forecast variance of foreign import and export transactions arising from the disturbance of the total volume of cross-border e-commerce transactions. It can be found that the standard deviation of the first forecast of the total volume of foreign import and export transactions is equal to 0.144636 , and the standard deviation of the second forecast is 0.145142 , which is larger than that of the first forecast, because the forecast in the second period includes the impact of the uncertainty of the total volume of cross-border e-commerce transactions in the first forecast, and the standard deviation of the total volume of foreign import and export transactions is gradually increasing with the increase of the number of forecast periods.

\section{Conclusion}

After putting forward the "Belt and Road" initiative, our government is vigorously promoting the development of cross-border e-commerce business, based on this background, the development of cross-border e-commerce in our country is changing the traditional mode of international trade step by step with its unique advantages. Based on the statistical data of China from 2004 to 2018, this 
paper establishes a vector auto-regressive model to analyze the relationship between the total amount of cross-border e-commerce transactions and the total amount of import and export trade in China.

(1) There is a long-term stable equilibrium relationship between the total amount of cross-border e-commerce transactions in China and the total amount of import and export trade in China;

(2) There is a one-way Granger causality between the total amount of cross-border e-commerce transactions in China and the total amount of import and export trade in China;

(3) In the short term, the impact of the total amount of cross-border e-commerce transactions on the total amount of import and export trade in China is relatively obvious. However, over time, the gradual accumulation of periods, the impact can be clearly seen: gradually reduced and tended to a stable state;

(4) The state should continue to strengthen its support for cross-border e-commerce platforms so as to promote their development and then influence the development of China's foreign trade.

\section{Countermeasures}

Based on the current development of cross-border e-commerce and import and export trade in China and the results of empirical analysis, the following countermeasures are proposed for reference:

\subsection{Improving infrastructure}

At present, our country is in the stage of cross-border e-commerce 3.0, although the development chain of cross-border e-commerce has been gradually formed, but there are still some problems such as imperfect tariff mechanism, insufficient supervision of relevant institutions and some loopholes, which will seriously affect the development space of cross-border e-commerce, and then affect the foreign import and export trade of our country. Therefore, the improvement of infrastructure is the first to bear the brunt.

\subsection{Improve relevant laws and regulations}

In order to clarify the interests and responsibilities of the relevant parties, it is necessary to further improve the relevant legal responsibilities, to regulate some of the existing laws and more clearly the standard rules, and to urge the relevant legal departments to strengthen the supervision, because cross-border e-commerce involves a number of countries, the laws and policies of different countries are different, and the improvement of the details of the laws and regulations can prevent the situation of "wiping the ball ".

\subsection{Positioning and Precision Talent Training}

At present, the major colleges and universities are basically independent of the two majors of e-commerce and international trade, the main characteristics of fresh graduates are solid professional knowledge, but the ability to combine the two is not enough and the ability of hands-on practice is poor, so in the training of talent, the professional can be separated into a single aspect of training, such as e-commerce can separate the direction of cross-border e-commerce, additional knowledge of relevant international trade, and increase the practical class hours to improve the hands-on ability of students.

\section{Acknowledgements}

The project was supported by research project for Fujian Education Department (Grant No. JAS 180197).

\section{References}

[1] He Hong. A preliminary analysis of the development of e-commerce and regional differences in 
China. Lanzhou University, 2016.

[2] Wenlong Zhu, Jian Mou, Morad Benyoucef. Exploring purchase intention in cross-border E-commerce: A three stage model. Journal of Retailing and Consumer Services, 2019, 51.

[3] Zhong Lingling, Li Hui. Empirical study on the impact of cross-border e-commerce on China's import and export trade. Business Economics Research, 2018(14):143-145.

[4] Dai Zongqun. Empirical analysis of the impact of cross-border e-commerce on China's import and export trade. Modern Marketing (next issue), 2018(08):174-175.

[5] Zan Jinmiao. Empirical analysis of the impact of cross-border e-commerce on import and export trade. National Circulation Economy, 2018(15):11-12.

[6] Xiao Ying. An empirical study on the impact of cross-border e-commerce on traditional foreign trade: a pulse response analysis based on VAR model. Guangdong Economy, 2018(04): 68-78.

[7] Wang Xirong; Yu stable strategy. An empirical analysis of the interaction between cross-border e-commerce development and traditional foreign trade. Economics and Management Research, 2018, v.39; No.303, 80-87.

[8] Shen Guijuan. Research on the linkage development of logistics industry and tourism in Henan based on VAR model. Logistics Technology, 2014, 33(03): 121-123.

[9] Zhang Yiru, Deng Li, Zhang stop. An empirical study on the relationship between money supply and inflation. Brand (second half month), 2015(12):158.

[10] Yu Junnian. econometric software: use of eviews. Beijing: University of Foreign Economics and Trade Press, 2012: 278-279.

[11] Chai li: He Ruoran. Based on VAR model, the interaction effect analysis of cross-border e-commerce and foreign trade in China. Journal of Urumqi Vocational University, 2019, v.28; No.107, 20-26.

[12] Wei Qing. A study on the correlation between international commodity price fluctuations and changes in China's price level. Shandong Normal University, 2017. 